\title{
Understanding Policy Instruments for Steering Nonprofit Organizations in China: Only Carrots and Sticks?
}

Zejin Liu (zejin.liu@kuleuven.be) Steven Van de Walle (steven.vandewalle@kuleuven.be)

\begin{abstract}
Government-nonprofit relations in China have transformed over the past three decades. However, little is known about how this transformation is reflected in the policy instruments used to steer nonprofits. Building on policy instrument theory, this article explores what policy instruments have been used to steer nonprofits at the central level and how this use of policy instruments has changed over time. This article is based on a content analysis of 300 central-level policy documents on nonprofits using NVivo. Results show that 22 kinds of policy instruments have been used to steer nonprofits. We found a steep increase in the use of four categories of policy instruments for nonprofits: authority, incentive, information, and organization instruments. Policy instruments for nonprofits have advanced towards diversity, with an emphasis on indirect control such as embedding the Party branches into nonprofits. The central government continues to have a significant predisposition towards regulatory instruments, which have evolved from ex-ante regulation to process and ex-post regulation. This article contributes to the literature on government-nonprofit relations by identifying policy instruments for nonprofits.
\end{abstract}

Keywords: Nonprofits, Policy instruments, Government-nonprofit relations, China 


\section{Introduction}

Over the past three decades, along with market-oriented economic reform, China has witnessed an explosion of nonprofit organizations, in both scale and scope ${ }^{1}$. By 2017 more than 762,000 nonprofit organizations have been officially registered with the Ministry of Civil Affairs (MCA) (MCA 2017). Some scholars estimate that there may actually be between 2 million and 8 million additional unregistered nonprofit organizations in China (Shieh 2013; Simon 2013). It is believed that the number of nonprofit organizations will continue to expand in China.

These nonprofit organizations now operate and function in a broad range of fields. Two notable examples are service provision by human service organizations (Shieh and Deng 2011; Jing and Gong 2012; Jing and Hu 2017), as well as policy advocacy by environmental NGOs (Tang and Zhan 2008; Zhan and Tang 2013; Li, Lo, and Tang 2015). More specifically, through providing policy recommendations for local authorities and supporting local environmental movements, environmental NGOs have played a critical role in environmental governance in Western China (Ho 2001; Cooper 2006). Human service organizations engaged in elderly care, child care, disability service, etc., have blossomed in many cities (Fulda, Li, and Song 2012; Li 2013). Suffice to say, nonprofit organizations have increasingly become an indispensable force in influencing the social landscape in China.

Meanwhile, the Chinese government has exerted profound impacts on nonprofit development and shaped particular government-nonprofit relations. The epochal transformation of China since the late 1970s made it possible for nonprofit organizations to emerge. During the 1980s, the political environment for nonprofit development was relatively free. After the crisis in June 1989, the central government was forced to rethink nonprofit policy and took serious measures to constrain nonprofit development, as nonprofit organizations were seen as a potential political threat. With ever-deepening 
reforms and emerging governance challenges, the central government has sought continuous and incremental adjustments for nonprofit policy.

Much scholarly attention has been paid to government-nonprofit relations, especially emphasizing many aspects of the political, legal and regulatory system may play an enabling or a restrictive role in nonprofit development (Anheier 2005). However, we still know little about how these institutional aspects are reflected in the policy instruments for nonprofit organizations. There is an array of policy instruments for nonprofit organizations, but to date these instruments have not been systematically investigated. Any adjustment of the relationship between government and nonprofits can be embodied through the change in the use of policy instruments for nonprofit organizations. Despite the academic and practical importance of this issue, it is not adequately answered by the existing research.

Scholars in China Studies have employed a case-study approach to understand how the Chinese government intervenes in the nonprofit sector (Kwong 2004; Hsu and Hasmath 2014; Hsu, Hsu, and Hasmath 2017). Although these studies offer significant insights, one can raise a serious objection that too much disaggregation of China's nonprofit policy "will mean losing sight of national patterns" (Perry 1994, 712). In addition, it is often taken for granted that the Chinese government utilizes a "carrot-and-stick" strategy to steer nonprofit organizations. However, this conventional wisdom may have prevented us from thoroughly understanding the diversity and complexity of policy instruments for steering nonprofit organizations in China.

Therefore, using policy instrument theory, this article will identify the policy instruments the central government has used to steer nonprofit organizations and describe how this use of policy instruments has changed over time, through a content analysis of policy documents ${ }^{2}$. This study will contribute to the literature on government-nonprofit relations by identifying policy instruments for nonprofits. Understanding these instruments helps 
us disentangle the underlying mechanisms of interventions designed for nonprofits. This study will also extend the understanding of the governing strategy for nonprofits in China. The central government has employed diverse policy instruments to steer nonprofit organizations, not just a "carrot-and-stick" strategy.

In the following sections, we will first provide a background on government-nonprofit relations in China, followed by the theoretical perspective of the study. Then we will describe our data and measurement method. Based on a content analysis of policy documents, we will empirically analyze the policy instruments used to steer nonprofits and their variations over time. Finally, this article will conclude with the empirical findings and discuss the theoretical implications and the research limitations.

\section{Background: Changes in Government-Nonprofit Relations in China}

Government-nonprofit relations in China have changed over the past three decades. This article will briefly describe this change based on two dimensions: the power relationship between government and nonprofits, and the degree of nonprofit autonomy. Figure 1 provides a continuum of government-nonprofit relations in China. On the left-end side is the repression relationship, in which the government overwhelmingly dominates nonprofits and nonprofits almost do not have autonomy. On the right-end side is the collaboration relationship, in which the government maintains some control over nonprofits but nonprofits possess a fair degree of autonomy. In between are various relationships with relative balance of power relationship and differential degree of nonprofit autonomy. It is important to note that this relationship continuum is used not to present any comprehensive description of government-nonprofit relations in China, but to provide a point of reference and a research context.

\section{[Insert Figure 1 about here]}

During the early 1980s, some types of nonprofit organizations were allowed to provide 
social services, such as professional associations and industry associations (Burns 1999; 2001). The Chinese central government issued stringent regulations to repress the rise of nonprofit organizations in the wake of the Tiananmen Square protests in 1989. Nonprofit organizations were first subject to a strict registration process and then to operations within a narrowly defined scope. The state power imposed overwhelming control over nonprofits, and nonprofits had the lowest degree of autonomy from government.

Despite slowing nonprofit growth, these regulations did not hinder the development and expansion of nonprofit organizations during the 1990s. The central government thus gradually adjusted nonprofit policy and reluctantly accepted nonprofit organizations. In the 1993 and 1998 administrative reform, the central government proclaimed an effort to “change governmental functions", namely "strengthening government's macro-control while weakening government's micro-intervention" (Lan 1999; Chan and Drewry 2001). In order to achieve this vision, the central government adopted a differential treatment strategy for nonprofits based on nonprofit missions. More specifically, nonprofits supporting democratic claims continued to be controlled by government, while nonprofits focusing on service provision were allowed to cooperate with government (Kang and Han 2008). During this period the central government continued to exert tight control over nonprofits, but nonprofits gained little autonomy.

From the 2000s onwards, the official tone towards nonprofit organizations has increasingly become more positive. In 2006, the central government proclaimed a grand blueprint devoted to building the "social management system" relying on the collaboration among the Chinese Communist Party (CCP), governments, nonprofits and citizens. This blueprint de facto endowed the work of nonprofits with legitimacy. Following the $18^{\text {th }}$ CCP National Congress in 2012, the central government called on nonprofits to play a bigger role in service provision. Government funding and nonprofit incubators were used to support nonprofit development across provinces. The 2013 administrative reform 
required that governments in each province should be committed to delegating power to nonprofits (Gao and Tyson 2017). After that, the central government abolished the "dual administration system" for particular types of nonprofits. This abolition means that most nonprofits can register directly with the MCA, without the requirement of affiliation to a professional supervisory agency anymore (State Council 2013). Despite easing the registration regulation, the central government had attached more emphasis on embedding the Party branches into nonprofits since 2012. The implications of this embeddedness for nonprofits need to be carefully examined. To sum up, during this period the central government maintained some control over nonprofits and nonprofits gained a fair degree of autonomy.

Nonprofit development and administrative reforms in China have provoked many debates on China's government-nonprofit relations. An emerging consensus in the literature is that government-nonprofit relations in China have gradually changed from tight government control over nonprofits to symbiotic interrelations between government and nonprofits (Saich 2000; Spires 2011; Zhang 2015). In this vein, government-nonprofit relations in China currently have a few distinct characteristics: the government (a) supports nonprofit development through various financial incentives and non-monetary support; (b) permits the expansion of a fairly autonomous nonprofit organizations; (c) takes indirect measures to steer nonprofit organizations (e.g., embedding the Party branches into nonprofits); (d) collaborates with nonprofit organizations that refrain from democratic claims and address social needs (Wei 2017; Huang 2018; Bies and Kennedy 2019).

\section{Theoretical Perspective: Understanding Government-Nonprofit Relations through Policy Instrument Theory}

As a prevailing theory, government-nonprofit relations have been explained through many theoretical models, such as the supplementary model and the complementary model 
(Salamon 1987; 1995). These models are all based either on a service role or on an advocacy role of nonprofit organizations. Theoretical advance has thus been limited by this nonprofit-centered perspective or a bottom-up approach. This study will not continue to center on the roles played by nonprofits to understand government-nonprofit relations. By contrast, we will turn our attention to the actions by government to influence nonprofits. Grounded in policy instrument theory, our central concern in this study is to systematically investigate how the central government responds to the two key roles played by nonprofits in China.

\section{Policy Instrument Theory: A Typology Approach}

Policy instruments are the techniques and means by which governments attempt to address policy problems and achieve policy goals. Studies on policy instruments normally concentrate on policy instrument taxonomy, choice, outcome, and roles of policy instruments embodied in the policy process. Over the past decades, policy instrument theory has become popular and has been widely used to understand policy issues. Scholars in public policy have made many attempts to identify the policy instruments the government has used and to sort them into meaningful categories. However, there is no significant scholarly consensus on the classification of policy instruments. As Salamon (2002, 21) noted, "the tools of public action rarely appear in pure form". The multidimensionality of policy instruments complicates the task of describing and classifying these instruments. However, this diversity of policy instruments should be viewed not as a drawback, but as a strength. Various classifications of policy instruments are largely appropriate, as different classifications will highlight different facets.

\section{Classification of Policy Instruments}

Present studies of policy instrument typology have been influenced by Lowi's early efforts 
to classify public policies. According to the criterion of coerciveness, Lowi (1972) sorts public policies as four types: distributive, regulative, redistributive, and constituent policy. Under the influence of Lowi's work, McDonnell and Elmore (1986) focus on the strategies of government intervention. These strategies are further divided into four categories of policy instruments: mandates, inducements, capacity-building, and system changing. Building on behavioral assumptions, Schneider and Ingram (1990) categorize policy instruments as authority tools, incentive tools, capacity tools, symbolic and hortatory tools, and learning tools. In addition, based on the extent of force that each instrument involves Bemelmans-Videc, Rist and Vedung (1998) identify three policy instruments in a metaphorical form: sticks, carrots and sermons, denoting regulations, subsidies and information programs, respectively.

According to the government resources each instrument enlists, Hood (1983, 4-6) generalizes four categories of policy instruments: authority, treasure, nodality, and organization instruments, denoting "the power officially to demand, forbid, guarantee, adjudicate", "the possession of a stock of moneys or "fungible chattels", "the property of being in the middle of an information or social network", and "the possession of a stock of people with skills, land, buildings, materials and equipment, somehow arranged", respectively. On the other hand, Salamon (2002) and Howlett (2011) identify a host of basic policy instrument components in a systematic way, such as direct government regulation, tax incentives, public information, and administrative advisory committees. These instrument components now have been widely used by scholars to analyze relevant policy issues. What is more, Howlett (2011) expands the policy instrument typology by Hood in depth and integrates basic instrument components into the four categories of policy instruments (see Figure 2).

[Insert Figure 2 about here] 


\section{Policy Instruments for Nonprofits: The Case of China}

In this study, policy instrument theories by Salamon, Hood and Howlett will be used as the key theoretical framework to identify and sort policy instruments for steering nonprofits in China. Most of the original policy instruments are directly applicable to understand intervention strategies designed for nonprofit organizations. The theoretical framework for this study will adopt the notion called "incentive instruments" to include material and non-material rewards to nonprofit organizations, rather than the "treasure instruments" originally used in the authors' works.

In addition, this study will theoretically justify one policy instrument called "CCP embeddedness". Undoubtedly, this instrument is special for the Chinese context. CCP embeddedness means that the Chinese government strives to embed the Party branches into internal structures of nonprofit organizations (Thornton 2013; Xiao and Lin 2016). The specific strategies of this embeddedness include incorporating nonprofit managers and important employees into the CCP, establishing the Party branches within nonprofits or the joint Party branches among different nonprofits, etc. Despite containing some elements reflecting authority, CCP embeddedness will be conceptualized as one kind of organization instruments, since the Chinese government utilizes the CCP system to steer nonprofits. The Party branches embedded in nonprofits give governments the physical ability to act and intervene directly. As a result, there is reason to believe that this institutionalized arrangement has significant implications for nonprofit autonomy and government-nonprofit relations in China.

\section{The Link between Government-Nonprofit Relations and Policy Instruments}

Theoretically, government-nonprofit relations can be embodied not just by how governments interact with nonprofits through public organizations and officials, but also by how governments are linked with nonprofits through public policies. Policies are 
collections of instruments aimed at diverse objectives. In order to achieve policy objectives, the government will apply various policy instruments to the circumstances of a particular problem. As a result, this study developed the theoretical framework mentioned above by linking the classical literature on government-nonprofit relations with insights from policy instrument theory. Public actions to influence nonprofits can be understood by systematically analyzing policy instruments for nonprofits. This study, by identifying and sorting policy instruments for steering nonprofits, will lay the groundwork for future research on nonprofit policy in China.

\section{Research Method}

\section{Data Collection}

In order to trace the policy instruments used to steer nonprofit organizations at the central level, a novel data set was compiled from policy documents on nonprofits published by the central-level agencies between 1989 and 2018. These policy documents, including laws, regulations, rules, memos and other types of documents, were drawn from the Public Service Platform of Nonprofit Organizations in China (http://www.chinanpo.gov.cn/index.html), in which information on registered nonprofits, policy documents on nonprofits, nonprofit demonstration projects, administrative penalties for nonprofits, etc., are publicly available. This platform is endorsed by the National Bureau of Nonprofit Organizations Administration affiliated to the MCA. Table 1 provides a description of the data set.

\section{[Insert Table 1 about here]}

This platform provides a systematic inventory of central-level policy documents on nonprofits. A series of sub-issues of nonprofit policy in China are covered by these policy documents in the platform, such as registration regulations, regulatory agencies, employee training, financial incentives, and voluntary services. These policy documents were issued by different central-level agencies, including the organs of the CCP Central Committee, 
the National People's Congress (NPC), the State Council and its ministries, the Supreme Court, and the Supreme Procuratorate. The materials generated by these central-level agencies are officially called "central-level documents". Therefore, policy documents on nonprofits in the platform are comprehensive enough to analyze policy instruments for nonprofits at the central level. Based on these policy documents, a content analysis will be used to identify and sort policy instruments for nonprofits and to describe variations in the use of policy instruments for nonprofits over time.

\section{Measurement}

In order to analyze number, categories, and changes in policy instruments for nonprofits from a host of central-level policy documents, the qualitative data analysis software NVivo 11.0 was adopted to facilitate our text analysis.

We first coded these texts in accordance with the original instrument components mentioned above. Coding was conducted manually and our coding mainly complied with three criteria: First, if one document concentrates on a particular theme, such as government purchase-of-service or tax reliefs to nonprofits, the whole text would be coded as one node and assigned to a certain instrument node, such as government procurement or tax incentives. Second, if one document focuses on an abstract theme, such as boosting nonprofit development, the paragraphs reflecting different themes within the document would be coded and assigned to different instrument nodes. Third, different sentences would be coded and assigned to particular instrument nodes if more than one core meaning exists within a paragraph.

After completing the coding, we used the framework matrix function to summarize coding results. More specifically, a framework matrix was created to summarize what policy instruments have been employed and emphasized, as well as to explore what changes have taken place in the number of policy instruments over time. In this way, these instrument 
nodes were grouped together to provide a systematic inventory of policy instruments found in China's nonprofit policy over the past three decades.

Furthermore, we visualized connections among these instrument nodes using the sociograms function. This function can conceptualize increasingly complex and accumulative nodes and allow nodes to be presented diagrammatically (Hutchison, Johnston, and Breckon 2010). In this study, associative relationship with no directionality and one-way relationship were selected to connect, aggregate, and categorize these instrument nodes. The former relationship can be used to demonstrate that items are affiliated in some way. For example, two people know each other. The latter relationship can be used to demonstrate a relationship between items which has a definite direction. For example, industrial waste degrades water quality. The two relationships imply that, for instance, the data for "prohibition" and for "standards" can be integrated into the category "authority instruments" and into the category "information instruments", respectively. On the other hand, the two instrument categories associate with each other in this study. After that, we analyzed variations in the use of four categories of policy instruments for nonprofits.

However, a caveat is warranted. In this study, one potential drawback of the data is data imbalance over time. Our analysis results may thus be flawed and biased as more recent policy documents on nonprofits have been digitized and preserved better than the earlier documents. In addition, one problem of the method is that this content analysis cannot fully take variation in importance of policy documents into account. In order to alleviate the two drawbacks and check the robustness of our empirical results, 36 key policy documents were selected and analyzed again. The 36 key policy documents include 8 laws promulgated by the NPC, 14 regulations issued by the State Council, 14 documents published by the CCP General Office and/or the General Office of the State Council.

\section{Empirical Findings}




\section{Policy Instruments for Steering Nonprofits in China}

\section{Specific Policy Instrument Components}

The first question we posed was to identify what policy instruments have been used by the central government to steer nonprofits over the past three decades. As shown in Table 2, we found that, in total, 22 kinds of specific policy instruments have been employed to influence nonprofits in China. Policy instruments such as "regulatory procedures", "tax incentives", "information and provision of advice", and "administrative coordination", have all been identified. Typical examples are shown in Table 2 to define and illustrate each policy instrument.

Our results show that, "regulatory procedures" (123 nodes), "information and provision of advice" (56 nodes), "regulatory agencies" (51 nodes), "demonstration and incubation" (43 nodes), "tax incentives" (40 nodes) are the top five policy instruments for steering nonprofits, accounting for $52.2 \%$ of the total population. This finding indicates that regulations, financial incentives, and information have been widely adopted to influence nonprofits in China. However, the number for regulations is far bigger than that for financial incentives and for information.

The special policy instrument called "CCP embeddedness", has been attached more emphasis at the central level over the past ten years. The number of this instrument in the third ten-year period has increased by 18 times as against that in the second ten-year period. In other words, the government has relied on the Party branches within nonprofits more often to supervise or direct activities of nonprofits. This finding indicates that the central government has paid particular attention to taking an indirect mean to steer nonprofits, in the wake of the relaxation of registration regulation. There is reason to believe that this instrument has had fundamental implications for nonprofit autonomy and governmentnonprofit relations in China.

[Insert Table 2 about here] 


\section{Four Categories of Policy Instruments}

According to the government resources each instrument enlists, this study attempted to categorize these specific policy instruments mentioned above. More specifically, policy instruments involving coercive power, property or non-monetary incentives, information support, and organizational resources, were integrated into four categories of policy instruments for nonprofits: authority instruments, incentive instruments, information instruments, and organization instruments, respectively.

As Figure 3 shows, associative relationships and one-way relationships were used to connect and aggregate these specific policy instruments found in China's nonprofit policy. That is, for instance, we pooled the data for "regulatory procedures" and "regulatory agencies" into the category "authority instruments", for "tax incentives" and "rewards" into the category "incentive instruments", for "positive publicity" and "standards" into the category "information instruments", for "administrative coordination" and "CCP embeddedness" into the category "organization instruments".

\section{[Insert Figure 3 about here]}

\section{Diverse Policy Instruments Versus “Carrot-and-Stick" Strategy}

A popular scholarly consensus in the literature on government-nonprofit relations in China is that the Chinese government has used a "carrot-and-stick" strategy to steer nonprofits. On the one hand, various financial incentives, namely "carrots", have been adopted to coopt nonprofits, while stringent registration regulations and inspection procedures, namely "sticks", have been employed to control nonprofits on the other. Indeed, financial incentives and regulations are widely used intervention strategies for nonprofits However, as mentioned above, our results show that diverse policy instruments have been used to steer nonprofits and the governing strategy for nonprofits is far more complex than the "carrot-and-stick" strategy. In short, the four categories of policy instruments - authority 
instruments, incentive instruments, information instruments, organization instruments have been used to steer nonprofits over the past three decades, not only a "carrot-andstick" strategy.

\section{Changes in the Adoption of Policy Instruments for Nonprofits over Time}

\section{The General Picture}

The second question we posed was to describe how the use of policy instruments for nonprofits has changed over time. For this purpose, the coded nodes per five-year period were grouped together to provide the complete inventory of policy instruments for steering nonprofits in China (see Appendix 1).

Figure 4 shows variations in the number of the four categories of policy instruments in different periods. We found that the four categories of policy instruments all show an increasing trend. More specifically, we only saw that authority instruments ( 7 nodes) are used to control nonprofits in the first five-year period (1989-1993). However, the number of authority instruments, incentive instruments, information instruments, and organization instruments rises to 107 nodes, 82 nodes, 89 nodes, and 69 nodes respectively in the sixth five-year period (2014-2018). In addition, the past five years (2014-2018) have witnessed a sharp upward trend in the use of policy instruments for steering nonprofits. The number of instrument nodes in the past five years accounts for $57.8 \%$ of the total population. This finding reveals that the central government has paid unprecedented attention to nonprofits in recent years.

\section{[Insert Figure 4 about here]}

Our results show that policy instruments for nonprofits have become more diverse in recent years. During the period 1989-1993, only authority instruments, namely direct government regulation, were employed to control the rise of nonprofits, while 20 kinds of policy instruments were adopted to influence nonprofits during the period 2014-2018. 
A significant shift of policy instruments for nonprofits, from uniform regulations to diverse policy instruments, has taken place over time. The service provision role of nonprofits has been increasingly accepted by the Chinese government. As a result, despite maintaining some control over nonprofits, the central government has taken a diverse range of measures to support the development of nonprofits. In short, the relationship between government and nonprofits in China has changed from a repression relationship to a collaboration relationship in many fields.

Our results also show that the central government has a significant preference for authority instruments. More specifically, authority instruments, incentive instruments, information instruments, and organization instruments are respectively responsible for $36.8 \%, 23.2 \%, 24.8 \%$, and $15.2 \%$ of the total population. The category "authority instruments" makes up a relatively high share. In addition, three other specific policy instruments, namely "information and provision of advice", "standards", and "CCP embeddedness", also contain some elements reflecting authority or coerciveness. The three policy instruments were integrated into "information instruments" or "organization instruments", though. For this reason, authority instruments are the most widely used instruments to steer nonprofits.

\section{Changes in the Use of the Four Categories of Policy Instruments}

In order to describe changes in the use of the four categories of policy instruments in depth, we further extracted and analyzed the texts of these central-level policy documents.

Authority Instruments: from Ex-ante Regulation to Process and Ex-post Regulation In this study, "regulatory procedures", "regulatory agencies" and "prohibition" were integrated into "direct government regulation". Our results show that the number of policy instruments reflecting "direct government regulation" in the sixth five-year period 
has increased by almost 14 times as against that in the first five-year period.

This finding is not consistent with the popular idea that regulation on nonprofits in China has significantly relaxed in recent years. We found that, by analyzing the texts, the central government has relaxed ex-ante regulation, namely registration regulation, but also strengthened process regulation and ex-post regulation on nonprofits. More specifically, according to the regulations in 1998, the establishment of nonprofits has two steps: nonprofits first have to look for a professional supervisory agency to supervise their activities, and then nonprofits can apply for an official registration. Undoubtedly, this registration regulation has exerted stringent control over nonprofits and stymied the growth of nonprofits.

The central government abolished this registration regulation in 2013. Most nonprofits can apply for an official registration directly, without the prerequisite of affiliation to a professional supervisory agency anymore. However, the relaxation of registration regulation does not mean the decline in the number of regulations on nonprofits. By contrast, in recent years, the central government has paid more attention to inspecting activities of nonprofits and evaluating performance of nonprofits. Notable examples are regulations on nonprofit information disclosure, administrative licenses for initiatives launched by nonprofits, and regulations on regular inspections of nonprofits. As a result, a significant shift from ex-ante regulation to process and ex-post regulation, has taken place within authority instruments.

Incentive Instruments: from Direct Financial Support to Indirect Government Control There is a sharp increase in the number of incentive instruments, especially the policy instruments related to "demonstration and incubation", "government funding", and "tax incentives". Our results show that the number of incentive instruments in the last ten years is 36 times larger than that in the 1990s. 
In the first ten-year period, the central government mainly adopted various regulatory instruments to control the development of nonprofits. Along with the changing context in China, the policy instruments for nonprofits preferred by the central government have shifted from coercive instruments, direct control to less coercive instruments, indirect control. This study joins the findings by Kang and Han (2008). They argue that the Chinese government has developed a "system of graduated controls" for nonprofits, in which nonprofits challenging the state power will be controlled by government, while nonprofits providing public services will be supported by government.

As for nonprofits devoted to service provision, a wide range of incentive instruments have been used to encourage nonprofits to undertake activities desired by government. These incentives include nonprofit development initiatives launched by local governments, purchase-of-service, tax reliefs to nonprofits, government subsidies to nonprofit employees, etc. On the one hand, these financial resources indeed support the development of nonprofits and benefit their operations. On the other hand, these resources increase the risk of resource dependence on government funding, and the loss of nonprofit mission and autonomy. In this vein, these incentive instruments can be viewed as an indirect control strategy that directs nonprofit behaviors congruent with official desires.

Information Instruments: from Explicit Regulation to Implicit Regulation Similar to the incentive instruments mentioned above, this study saw a very sharp increase in the number of information instruments. Information instruments have become the second most widely used category of policy instruments for steering nonprofits, next to authority instruments.

In this study, information instruments for nonprofits are efforts to utilize information available to government to direct nonprofit behaviors. These information instruments 
include public information, non-monetary support (e.g., expertise), voluntary appeals, etc. On the one hand, it is a fact that professional knowledge or skills and systematic evaluation indicators have been provided to nonprofits to improve their capacities. On the other hand, we found that particular information instruments have been used to implicitly regulate nonprofits within the context of already existing regulations.

The two instruments, "positive publicity" and "moral suasion and encouragement", can be used as two notable examples to illustrate the implicit regulatory function of information instruments. Positive publicity for nonprofits with good social reputation signals to local governments, nonprofits, and other relevant actors. The signal implies that what types of nonprofits, and what services provided by nonprofits are consistent with the expectation of the central government. Voluntary appeals can also be used to implicitly regulate nonprofits. For example, in recent years many nonprofits have been involved in the Poverty Alleviation Initiative in China to respond to official appeals. Nonprofits can not only earn good social reputation, but also develop social connections with local authorities through this involvement and participation. Otherwise, they may suffer troubles if official appeals are always ignored or go unfulfilled. As a result, we argue that the central government has attempted to steer nonprofits through the implicit regulatory function of policy instruments, in addition to explicit regulation.

Organization Instruments: from Input Orientation to Outcome Orientation Organization instruments were almost not used to influence nonprofits during the 1990s - early 2000s. However, the central government has relied on organization instruments more often in the past ten years. The number of organization instruments increased by more than 17 times in the last decade.

Over the past three decades, the central government has made efforts to reduce the size of administrative apparatus and to rationalize government-nonprofit relations in China. A 
notable example is that governments at all levels have gradually cut the official tie between government and industry or business associations. Despite decoupling the official tie between government and nonprofits, the Chinese government still needs nonprofits to continue to provide public services. For this reason, a more effective alternative is to adopt purchase-of-service, government-nonprofit partnership, and other market-oriented means to fulfill public service responsibility.

However, the central government also needs to protect the regime from potential political threats of nonprofits. Special agencies geared to this task have thus been utilized, such as embedding the Party branches into nonprofits. In addition, coordinating agencies or leading units have been created or designated to coordinate respective duties on supervising and empowering nonprofits. No matter decoupling official ties, adopting market-oriented instruments, or relying on particular agencies, the central government has placed more emphasis on an effective and more acceptable nonprofit policy.

\section{Robustness Check}

Considering the problems of potential data imbalance and variation in importance of documents, we selected 36 key policy documents and analyzed them again to alleviate the two problems and check the robustness of our empirical results. The 36 key policy documents include 8 laws, 14 administrative regulations with legal effects, and 14 other important documents. Our selection of policy documents are mainly based on two criteria: legal consequences and power structure. The core issues on which the very top of the hierarchy focuses, can be known by analyzing these key policy documents.

In total, 122 instrument nodes from the 36 key policy documents were extracted from our coded results. Appendix 2 shows the change of 122 instrument nodes over time. We found that the empirical results mentioned above are almost fully consistent with the results found in the 36 key policy documents. Despite showing an overall upward trend, 
the number of authority instruments, incentive instruments, and information instruments found in these key documents all fluctuates over time. To sum up, our empirical results are supported by the core concerns of the central government. In this article, however, we are not capable to assess whether the 36 key documents have had a greater impact on nonprofits than other central-level documents.

\section{Discussion and Conclusion}

The past three decades have witnessed the transformation of government-nonprofit relations in China. How this transformation is reflected in the policy instruments used to steer nonprofits, however, is still poorly understood. This article presents the first systematic description of policy instruments used by the central government to steer nonprofits, through a content analysis of central-level policy documents. Our results show that 22 kinds of specific policy instruments have been used to steer nonprofits over time, such as regulatory procedures, tax incentives, public information, and purchase-of-service. The frequency of use is, however, not equally distributed across these policy instruments. Regulations and financial incentives are the most widely used policy instruments for nonprofits. CCP embeddedness, which means the government strives to embed the Party branches into nonprofits, has been widely used in the wake of the relaxation of registration regulation. Policy instruments for nonprofits in China have become more diverse. The central government now focuses on how to use instrument mixes to result in synergistic effects on nonprofits, with an emphasis on indirect control over nonprofits. In short, the governing strategy for nonprofits in China is far more complex than it has ever been before, not only a "carrot-and-stick" strategy.

Building on policy instrument theories by Hood, Salamon and Howlett, This article integrated these specific policy instruments into four categories of policy instruments: authority instruments, incentive instruments, information instruments, and organization 
instruments. Our results show that the number of the four categories of policy instruments has dramatically increased over time. However, the majority of the four categories of policy instruments have been used in the past five years. This finding indicates that in recent years the Chinese central government has attached unprecedented importance to nonprofit organizations.

The central government continues to have a significant predisposition towards authority instruments, especially regulatory instruments. However, authority instruments have evolved from ex-ante regulation to process regulation and ex-post regulation. More specifically, the central government has relaxed registration regulation on nonprofits, but gradually strengthened the supervision of routine activities and the regular inspection of nonprofits. A large number of incentive instruments have been used to stimulate the growth of nonprofits in the past ten years. However, these financial incentives may lead to the loss of nonprofit autonomy and the distortion of nonprofit missions, and then nonprofits are strategically co-opted into the existing government system. Information instruments have been used to signal to governments, nonprofits, and other actors. The signals indicate to these actors where or what they perform is consistent with the expectation of the central government. In addition, organizational resources and the CCP system have also been widely employed to achieve particular policy objectives.

Our findings have clear implications for the literature on government-nonprofit relations and policymakers. First, the existing studies of government-nonprofit relations are mainly based either on the service role of nonprofits in public service provision, or on the advocacy role of nonprofits in public policy advocacy. Differing from a nonprofitcentered perspective or a bottom-up approach, this study explains government-nonprofit relations through a government-centered perspective and a top-down approach, especially centering on policy instruments for nonprofits. Any change in government-nonprofit relations can be embodied through changes in the use of policy instruments for nonprofits. 
Second, this study extends the understanding of the governing strategy for nonprofits in China by identifying policy instruments for steering nonprofits, especially theoretically justifying one policy instrument called "CCP embeddedness". This instrument may have fundamental implications for government-nonprofit relations in China. Third, our findings help policymakers improve their understanding of nonprofit policy. Policymakers need to take into account how to design appropriate policy instruments to fuel nonprofit development, on the premise of protecting nonprofit autonomy.

This study is subject to several limitations. First, we draw our conclusions through a content analysis of policy documents, but there may be a gap between policy rhetoric and policy practice. Second, we center on policy instruments for steering nonprofits at the central level, but variations in the use of policy instruments for nonprofits may exist across provinces in China. Third, we collect our data from an official database, but more recent policy documents have been digitized and preserved better than the earlier documents. However, this database is still the best data source compared with other possible options. We welcome future studies to explore policy instruments for nonprofits at the local level, and to compare variations in the use of policy instruments across provinces in China. Future studies can also explore how public officials select these policy instruments. 
Policy Instruments for Steering Nonprofits

\section{Notes}

${ }^{1}$ According to laws and regulations in China, nonprofit organizations basically include three major types: social groups, social service organizations (private non-enterprise entities) and foundations. The three types of nonprofit organizations cover a great diversity of entities. This study views nonprofit organizations in China as a single "sector", and does not distinguish these organizations.

${ }^{2}$ In this study, the central government refers to the organs of the CCP Central Committee, the NPC, the State Council and its ministries, the Supreme Court, and the Supreme Procuratorate in China, not only the State Council in the narrow sense.

\section{References}

Anheier, H. K. (2005). Nonprofit Organizations: Theory, Management, Policy. New York, NY: Routledge.

Bemelmans-Videc, ML., Rist, C. R., and Vedung, O. E. (1998). Carrots, Sticks, and Sermons: Policy Instruments and Their Evaluation. New Brunswick, NJ: Transaction Publishers.

Bies, A. and Kennedy, S. (2019). The state and the state of the art on philanthropy in China. VOLUNTAS: International Journal of Voluntary and Nonprofit Organizations, 30(4), 619633.

Burns, P. J. (1999). The People's Republic of China at 50: national political reform. The China Quarterly, 159, 580-594.

Burns, P. J. (2001). Public sector reform and the state: the case of China. Public Administration Quarterly, 24(4), 419-436.

Chan, CP. and Drewry, G. (2001). The 1998 State Council organizational streamlining: personnel reduction and change of government function. Journal of Contemporary China, 10(29), 553-572.

Cooper, M. C. (2006). 'This is our way in': the civil society of environmental NGOs in 
South-West China. Government \& Opposition, 41(1), 109-136.

Fulda, A., Li, Y., and Song, Q. (2012). New strategies of civil society in China: a case study of the network governance approach. Journal of Contemporary China, 21(76), 675-693.

Gao, H. and Tyson, A. (2017). Administrative reform and the transfer of authority to social organizations in China. The China Quarterly, 232, 1050-1069.

Ho, P. (2001). Greening without conflict? environmentalism, NGOs and civil society in China. Development and Change, 32(5), 893-921.

Hood, C. C. (1983). The Tools of Government. London, UK: The Macmillan Press.

Howlett, M. (2011). Designing Public Policies: Principles and Instruments. New York, NY: Routledge.

Hsu, J. Y. J. and Hasmath, R. (2014). The local corporatist state and NGO relations in China. Journal of Contemporary China, 23(87), 516-534.

Hsu, J. Y. J., Hsu, C. L., and Hasmath, R. (2017). NGO strategies in an authoritarian context, and their implications for citizenship: the case of the People's Republic of China. VOLUNTAS: International Journal of Voluntary and Nonprofit Organizations, 28(3), 11571179.

Huang, Y. (2018). At the mercy of the state: health philanthropy in China. VOLUNTAS: International Journal of Voluntary and Nonprofit Organizations, 30(4), 634-646.

Hutchison, A. J., Johnston, L. H., and Breckon, J. D. (2010). Using QSR-NVivo to facilitate the development of a grounded theory project: an account of a worked example. International Journal of Social Research Methodology, 13(4), 283-302.

Jing, Y. and Gong, T. (2012). Managed social innovation: the case of governmentsponsored venture philanthropy in Shanghai. Australian Journal of Public Administration, $71(2), 233-245$.

Jing, Y. and Hu, Y. (2017). From service contracting to collaborative governance: evolution of government-nonprofit relations. Public Administration and Development, 37(3), 191- 
Kang, X. and Han, H. (2008). Graduated controls: the state-society relationship in contemporary China. Modern China, 34(1), 36-55.

Kwong, J. (2004). Educating migrant children: negotiations between the state and civil society. The China Quarterly, 180: 1073-1088.

Lan, Z. (1999). The 1998 administrative reform in China: issues, challenges and prospects. Asian Journal of Public Administration, 21(1), 29-54.

Li, H., Lo, C. WH., and Tang, SY. (2016). Nonprofit policy advocacy under authoritarianism. Public Administration Review, 77(1), 103-117.

Li, Y. (2013). Disability service organizations and their relationship with the Chinese government: a case study in Beijing. The China Review, 13(2), 67-96.

Lowi, T. J. (1972). Four systems of policy, politics, and choice. Public Administration Review, 32(4), 298-310.

McDonnell, L.M. and Elmore, R.F. (1987). Getting the job done: alternative policy instruments. Educational Evaluation and Policy Analysis, 9(2), 133-152.

Ministry of Civil Affairs, PRC. (2017). Statistical communiqué on the 2017 social service and development. Retrieved from http://www.mca.gov.cn/article/sj/tjgb/

Perry, J. E. (1994). Trends in the study of Chinese politics: state-society relations. The China Quarterly, 139, 704-713.

Saich, T. (2000). Negotiating the state: the development of social organizations in China. The China Quarterly, 161, 124-141.

Salamon, M. L. (1987). Of market failure, voluntary failure, and third-party government: toward a theory of government-nonprofit relations in the modern welfare state. Journal of Voluntary Action Research, 16(1-2), 29-49.

Salamon, M. L. (1995). Partners in Public Services: Government-Nonprofit Relations in the Modern Welfare State. Baltimore, MD: JHU Press. 
Salamon, M. L. (2002). The Tools of Government: A Guide to the New Governance. Oxford, NY: Oxford University Press.

Schneider, A. and Ingram, H. (1990). Behavioral assumptions of policy tools. The Journal of Politics, 52(2), 510-529.

Shieh, S. and Deng, G. (2011). An emerging civil society: the impact of the 2008 Sichuan Earthquake on grass-roots associations in China. The China Journal, 65, 181-194.

Shieh, S. (2013). Chinese NGO Directory: 251 NGO Profiles and Special Report: China's Civil Society in the Making. Beijing: China Development Brief.

Simon, W. K. (2013). Civil Society in China: The Legal Framework from Ancient Times to the "New Reform Era”. Oxford, NY: Oxford University Press.

Spires, J. A. (2011). Contingent symbiosis and civil society in an authoritarian state: understanding the survival of China's grassroots NGOs. American Journal of Sociology, 117(1), 1-45.

State Council. (2013). The scheme for public sector reform and function change of the State Council. Retrieved from http://www.china.com.cn/news/2013lianghui/201303/14/content_28245220_3.htm

Tang, SY. and Zhan, X. (2008). Civic environmental NGOs, civil society, and democratization in China. The Journal of Development Studies, 44(3), 425-448.

Thornton, M. P. (2013). The advance of the Party: transformation or takeover of urban grassroots Society?. The China Quarterly, 213, 1-18.

Wei, Q. (2017). From direct involvement to indirect control? a multilevel analysis of factors influencing Chinese foundations' capacity for resource mobilization. VOLUNTAS: International Journal of Voluntary and Nonprofit Organizations, DOI 10.1007/s11266-0179924-3

Xiao, M. and Lin, H. (2016). Carrots and sticks: a case study of government-caused Danwei tradition in Chinese NGOs. VOLUNTAS: International Journal of Voluntary and 
Policy Instruments for Steering Nonprofits Nonprofit Organizations, 27(5), 2027-2036.

Zhan, X. and Tang ,SY. (2013). Political opportunities, resource constraints and policy advocacy of environmental NGOs in China. Public Administration, 91(2), 381-399.

Zhang, Y. (2015). Dependent interdependence: the complicated dance of governmentnonprofit relations in China. VOLUNTAS: International Journal of Voluntary and Nonprofit Organizations, 26(6), 2395-2423. 
Policy Instruments for Steering Nonprofits

\section{Tables, Figures and Appendices}

\section{Tables}

Table 1 Data Description

\begin{tabular}{cc}
\hline Years & Number of Policy Documents \\
\hline $1989-1993$ & 2 \\
$1994-1998$ & 11 \\
$1999-2003$ & 34 \\
$2004-2008$ & 46 \\
$2009-2013$ & 57 \\
$2014-2018$ & 150 \\
Total & 300 \\
\hline
\end{tabular}

Note: 1. The database of the public service platform of nonprofit organizations in China covers various policy documents from 1991 to 2018 (retrieved January 12, 2019). 2. The Regulations on the Registration Administration of Social Groups (Revised Edition), normally regarded as a very important regulation on nonprofit organizations in China, has come into force since February 2016. The 1989 Edition and the 1998 Edition were thus abolished and excluded from the official database. To ensure the completeness of policy documents, the two earlier editions were included in the data set in this article. 
Policy Instruments for Steering Nonprofits

Table 2 Specific Policy Instruments for Steering Nonprofits

\begin{tabular}{|c|c|c|}
\hline Policy Instrument Components & Number of Nodes & Notable Examples \\
\hline Regulatory Procedures & 123 & $\begin{array}{l}\text { Regulations on nonprofit } \\
\text { registration }\end{array}$ \\
\hline Information/Provision of Advice & 56 & $\begin{array}{l}\text { Explaining questions and doubts } \\
\text { about nonprofit issues }\end{array}$ \\
\hline Regulatory Agencies & 51 & $\begin{array}{l}\text { Obligations of supervisory agencies } \\
\text { for nonprofits }\end{array}$ \\
\hline Demonstration/Incubation & 43 & $\begin{array}{l}\text { Nonprofit demonstration projects } \\
\text { and nonprofit incubators }\end{array}$ \\
\hline Tax Incentives & 40 & $\begin{array}{l}\text { Tax reliefs and tax free to } \\
\text { nonprofits }\end{array}$ \\
\hline Administrative Coordination & 33 & $\begin{array}{l}\text { Coordinating agencies to fuel the } \\
\text { development of nonprofits }\end{array}$ \\
\hline Standards & 29 & $\begin{array}{l}\text { Performance evaluation indicators } \\
\text { for nonprofits }\end{array}$ \\
\hline Employee Training & 28 & $\begin{array}{l}\text { Providing knowledge and skills for } \\
\text { nonprofit employees }\end{array}$ \\
\hline Government Funding & 26 & Grants for incubating nonprofits \\
\hline Public-Private Cooperation & 25 & $\begin{array}{l}\text { Purchase-of-service contracting } \\
\text { with nonprofits }\end{array}$ \\
\hline Rewards & 24 & $\begin{array}{l}\text { Good social reputation or financial } \\
\text { rewards to nonprofits }\end{array}$ \\
\hline Prohibition & 23 & $\begin{array}{l}\text { Imposing a ban on profit-seeking } \\
\text { behaviors of nonprofits }\end{array}$ \\
\hline CCP Embeddedness a & 20 & $\begin{array}{l}\text { Establishment of the Party } \\
\text { branches within nonprofits }\end{array}$ \\
\hline Administrative Penalty & 19 & $\begin{array}{l}\text { Imposing penalties on nonprofits } \\
\text { failing to comply with regulations }\end{array}$ \\
\hline Moral Suasion/Encouragement & 18 & $\begin{array}{l}\text { Encouraging nonprofits to join the } \\
\text { Poverty Alleviation Initiative }\end{array}$ \\
\hline
\end{tabular}


Policy Instruments for Steering Nonprofits

Table 2 Continued

\begin{tabular}{lcl}
\hline Policy Instrument Components & Number of Nodes & \multicolumn{1}{c}{ Notable Examples } \\
\hline Positive Publicity & 18 & Advertising nonprofits with good \\
& 12 & social reputation \\
Government Re-organizations & 5 & government and nonprofits \\
Administrative Screening & & Inspecting work of nonprofits \\
Insurance Support & 3 & regularly \\
Fees/Charges & 2 & Purchasing insurances for nonprofit \\
Consultative Agencies & & employees \\
Land Support & 1 & Charges for nonprofit registration \\
\hline
\end{tabular}

Source: Adapted from Salamon (2002) and Howlett (2011).

a. Added by authors, not mentioned in the two references. 
Figures

Figure $1 \mathrm{~A}$ Continuum of Government-Nonprofit Relations in China

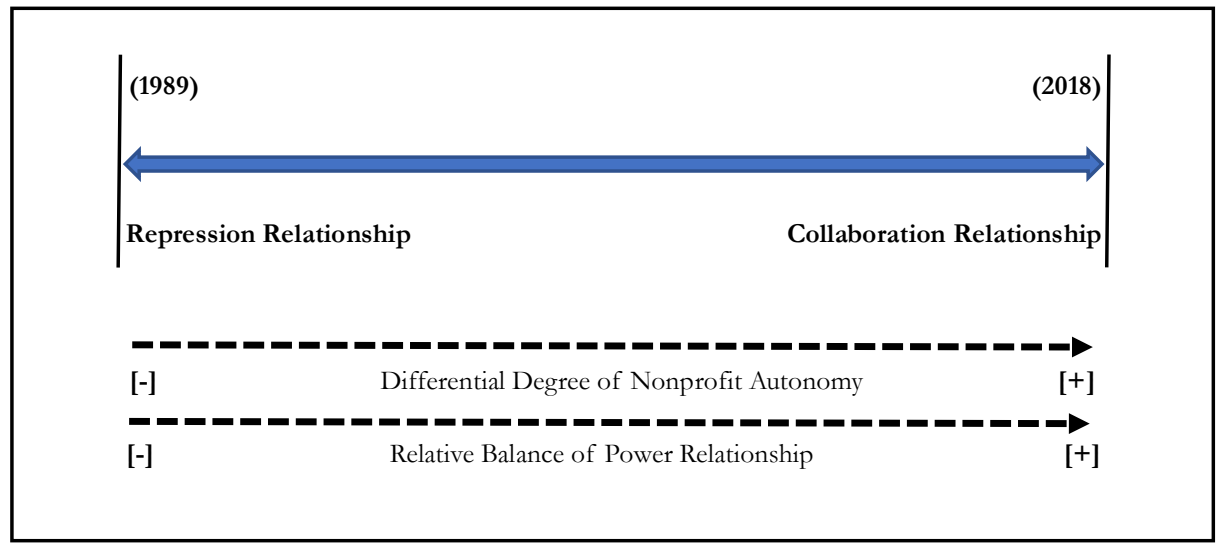

Figure 2 A Resource-Based Classification of Policy Instruments

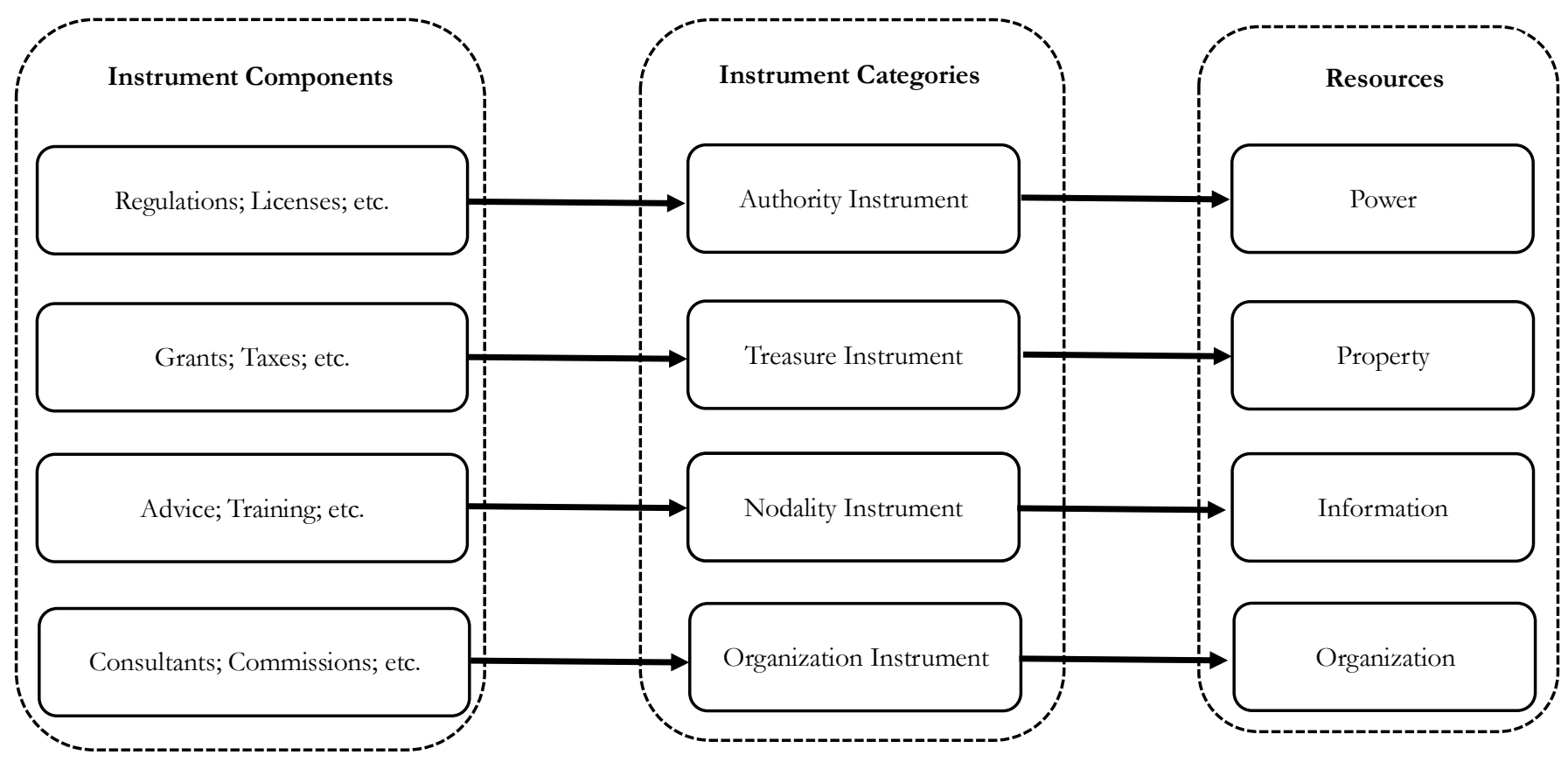

Source: Adapted from Hood (1983) and Howlett (2011). 
Figure 3 A Social Network Model of Policy Instruments for Steering Nonprofits

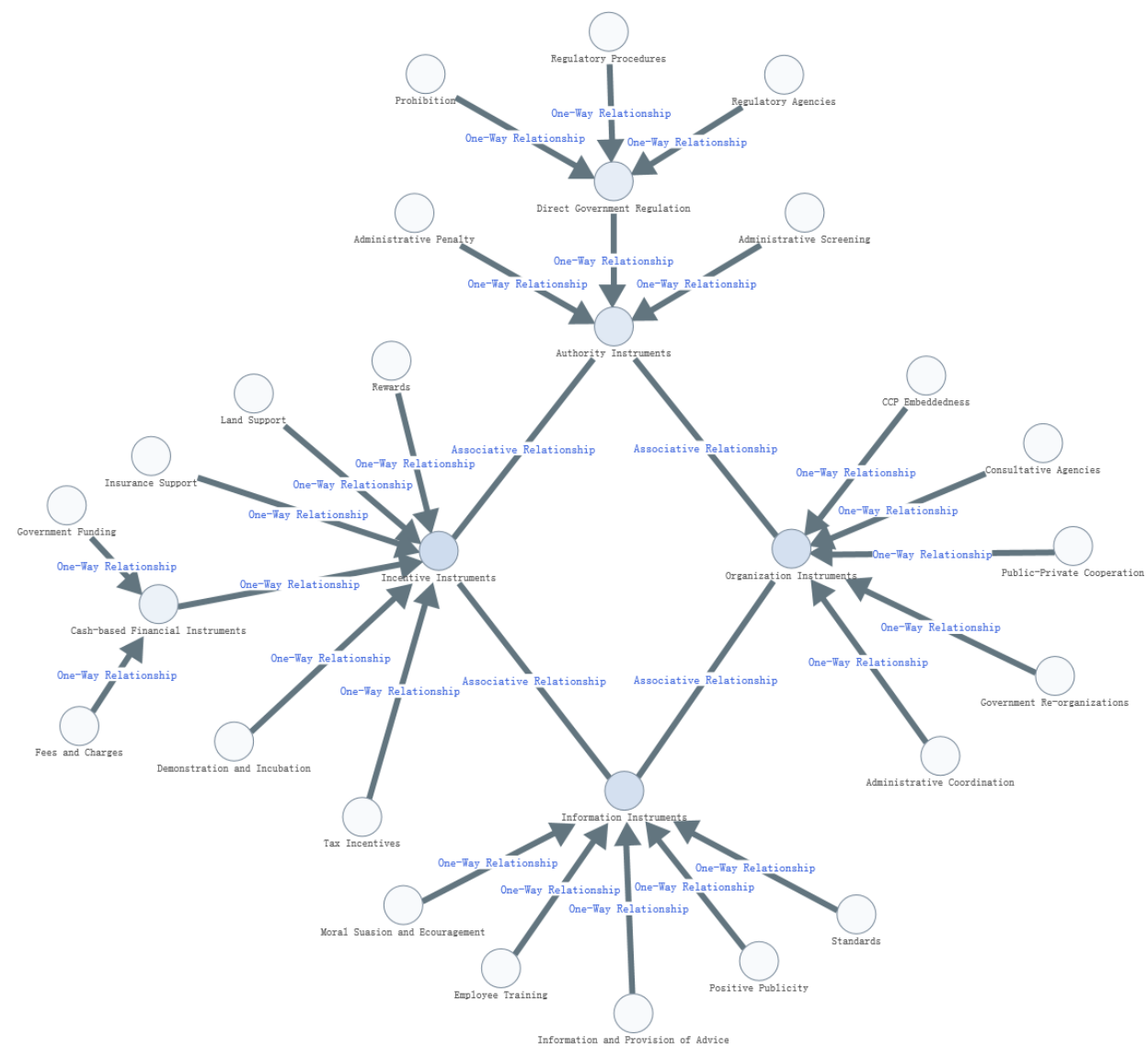

Figure 4 Numerical Variation in Policy Instruments for Steering Nonprofits

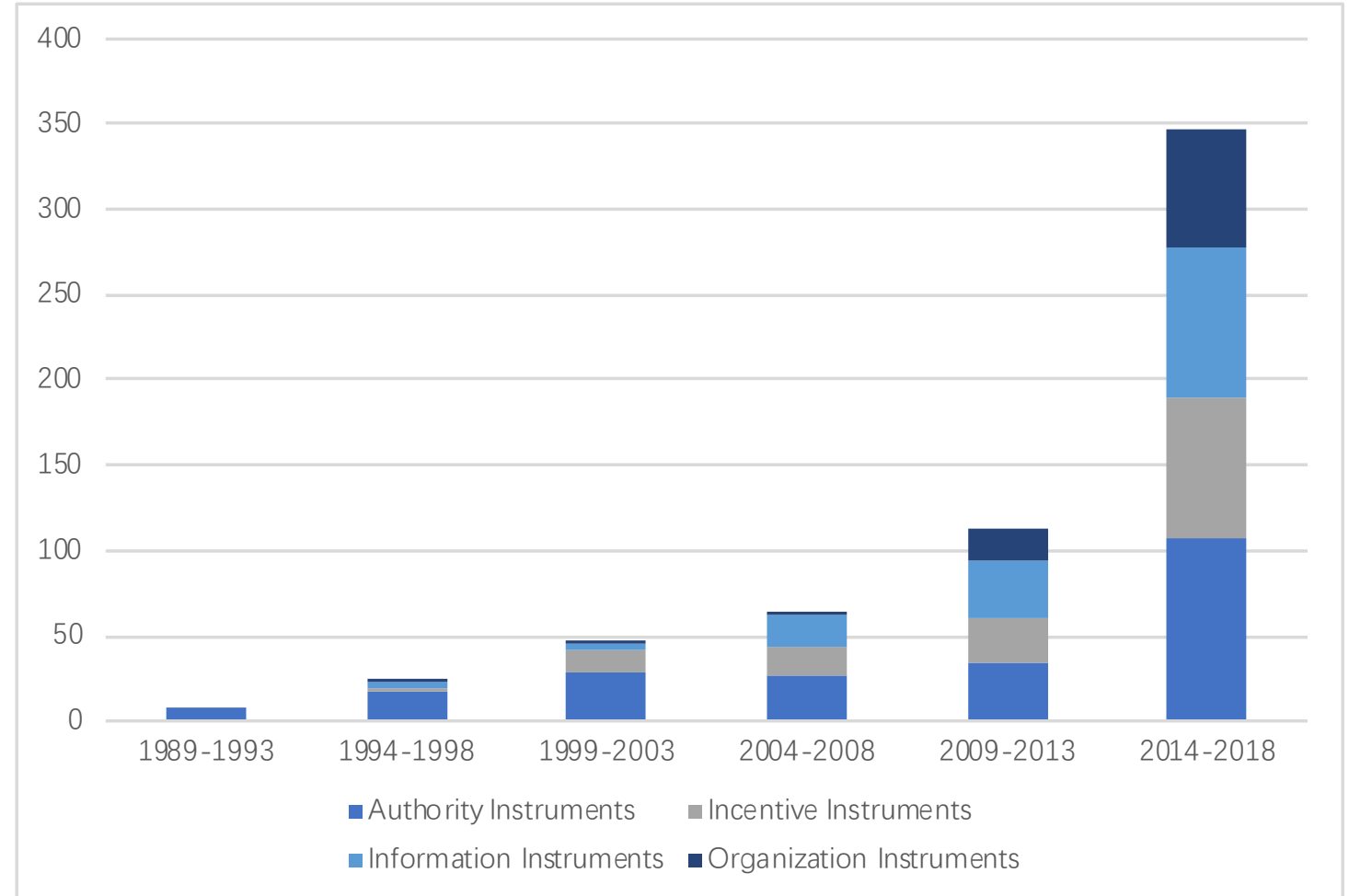


Appendix 1 Nodes of Policy Instruments from 300 Central-Level Policy Documents

\begin{tabular}{|c|c|c|c|c|c|c|c|}
\hline \multirow[b]{2}{*}{ Policy Instrument Categories } & \multirow[b]{2}{*}{ Policy Instrument Components } & \multicolumn{6}{|c|}{ Number of Nodes } \\
\hline & & 1989-1993 & 1994-1998 & $1999-2003$ & $2004-2008$ & $2009-2013$ & 2014-2018 \\
\hline \multirow{5}{*}{ Authority Instruments } & Regulatory Procedures & 4 & 5 & 19 & 12 & 18 & 65 \\
\hline & Regulatory Agencies & 2 & 5 & 6 & 5 & 8 & 25 \\
\hline & Prohibition & 1 & 4 & 3 & 4 & 5 & 6 \\
\hline & Administrative Screening & 0 & 0 & 0 & 3 & 1 & 1 \\
\hline & Administrative Penalty & 0 & 3 & 1 & 3 & 2 & 10 \\
\hline \multirow{7}{*}{ Incentive Instruments } & Tax Incentives & 0 & 3 & 8 & 7 & 5 & 17 \\
\hline & Rewards & 0 & 0 & 2 & 1 & 5 & 16 \\
\hline & Land Support & 0 & 0 & 0 & 0 & 0 & 1 \\
\hline & Insurance Support & 0 & 0 & 0 & 2 & 1 & 0 \\
\hline & Government Funding & 0 & 0 & 0 & 0 & 7 & 19 \\
\hline & Fees/Charges & 0 & 0 & 1 & 0 & 0 & 1 \\
\hline & Demonstration/Incubation & 0 & 0 & 1 & 6 & 8 & 28 \\
\hline \multirow{5}{*}{ Information Instruments } & Positive Publicity & 0 & 0 & 0 & 0 & 5 & 13 \\
\hline & Information/Provision of Advice & 0 & 2 & 3 & 6 & 5 & 40 \\
\hline & Standards & 0 & 0 & 1 & 7 & 10 & 11 \\
\hline & Moral Suasion/Encouragement & 0 & 0 & 0 & 3 & 5 & 10 \\
\hline & Employee Training & 0 & 0 & 0 & 3 & 10 & 15 \\
\hline
\end{tabular}


Appendix 1 Continued

\begin{tabular}{|c|c|c|c|c|c|c|c|}
\hline \multirow[b]{2}{*}{ Policy Instrument Categories } & \multirow[b]{2}{*}{ Policy Instrument Components } & \multicolumn{6}{|c|}{ Number of Nodes } \\
\hline & & 1989-1993 & 1994-1998 & 1999-2003 & 2004-2008 & 2009-2013 & 2014-2018 \\
\hline \multirow{5}{*}{ Organization Instruments } & CСP Embeddedness & 0 & 1 & 1 & 0 & 4 & 14 \\
\hline & Government Re-organizations & 0 & 0 & 0 & 1 & 0 & 11 \\
\hline & Public-Private Cooperation & 0 & 0 & 0 & 0 & 7 & 18 \\
\hline & Consultative Agencies & 0 & 0 & 0 & 1 & 0 & 0 \\
\hline & Administrative Coordination & 0 & 0 & 0 & 0 & 7 & 26 \\
\hline
\end{tabular}

Appendix 2 Nodes of Policy Instruments from 36 Key Policy Documents 
Policy Instruments for Steering Nonprofits

\begin{tabular}{|c|c|c|c|c|c|c|c|}
\hline \multirow[b]{2}{*}{ Policy Instrument Categories } & \multirow[b]{2}{*}{ Policy Instrument Components } & \multicolumn{6}{|c|}{ Number of Nodes } \\
\hline & & $1989-1993$ & 1994-1998 & $1999-2003$ & 2004-2008 & $2009-2013$ & 2014-2018 \\
\hline \multirow{5}{*}{ Authority Instruments } & Regulatory Procedures & 2 & 3 & 3 & 2 & 2 & 20 \\
\hline & Regulatory Agencies & 2 & 4 & 0 & 2 & 2 & 7 \\
\hline & Prohibition & 0 & 2 & 0 & 0 & 1 & 0 \\
\hline & Administrative Screening & 0 & 0 & 0 & 0 & 1 & 0 \\
\hline & Administrative Penalty & 0 & 2 & 1 & 2 & 1 & 3 \\
\hline \multirow{5}{*}{ Incentive Instruments } & Tax Incentives & 0 & 1 & 3 & 2 & 0 & 6 \\
\hline & Rewards & 0 & 0 & 0 & 0 & 0 & 1 \\
\hline & Land Support & 0 & 0 & 0 & 0 & 0 & 1 \\
\hline & Government Funding & 0 & 0 & 0 & 0 & 1 & 3 \\
\hline & Demonstration/Incubation & 0 & 0 & 0 & 0 & 0 & 3 \\
\hline \multirow{5}{*}{ Information Instruments } & Positive Publicity & 0 & 0 & 0 & 0 & 1 & 5 \\
\hline & Information/Provision of Advice & 0 & 1 & 1 & 0 & 1 & 5 \\
\hline & Standards & 0 & 0 & 0 & 0 & 0 & 2 \\
\hline & Moral Suasion/Encouragement & 0 & 0 & 0 & 0 & 1 & 1 \\
\hline & Employee Training & 0 & 0 & 0 & 0 & 0 & 2 \\
\hline \multirow{4}{*}{ Organization Instruments } & CCP Embeddedness & 0 & 0 & 0 & 0 & 0 & 4 \\
\hline & Government Re-organizations & 0 & 0 & 0 & 1 & 0 & 2 \\
\hline & Public-Private Cooperation & 0 & 0 & 0 & 0 & 1 & 4 \\
\hline & Administrative Coordination & 0 & 0 & 0 & 0 & 1 & 6 \\
\hline
\end{tabular}

